\title{
Science on trial
}

\section{The 2009 L'Aquila earthquake illustrates catastrophic shortcomings in the flow of information between scientists and the public.}

Earthquakes are unpredictable. The quake that struck the Italian town of L'Aquila on 6 April 2009 and killed 308 people was no exception. Indeed, only days before the event, a group of experts that advises the Italian Civil Protection Agency had concluded that a large earthquake in the area was unlikely, but could not be ruled out (Nature 465, 992; 2010). Despite the carefully placed caveats of their assessment of the situation, the six scientists on the committee are now being investigated on charges of manslaughter, because they did not call for people to be evacuated.

The case poignantly illustrates the difficulties of communicating uncertainty in science. The scientists had clearly stated at the meeting that a large earthquake was still possible. But their protestations were not taken seriously enough by the deputy technical head of the agency, who summarized the committee's conclusions at a press conference with the words: "The scientific community tells us there is no danger, because there is an ongoing discharge of energy. The situation looks favourable." A group of local citizens then filed a formal request for an investigation, claiming that many of the victims had planned to evacuate their homes, but changed their minds based on the committee's findings. The combination of summary, simplification and probably a degree of wishful thinking had led to a complete breakdown in the chain of communication between scientists and the public.

The outcome is disastrous on all fronts: people may have died or been injured unnecessarily; scientists are under charge of manslaughter for not predicting an event that is known to be perfectly unpredictable; and public trust in science has taken yet another battering.
The L'Aquila prosecutor's office will assess whether the call for an investigation has any merit. In the meantime, the scientific community is rushing to the aid of the scientists - for example, in a statement issued by the International Union of Geodesy and Geophysics (http://go.nature.com/qLKfu5). It is to be hoped that the seismologists of the Italian Major Risks Committee will not be prosecuted for giving imperfect advice to the best of their knowledge on an intractable problem. But, just as for El Niño predictions (Nature Geosci. 3, 231-232; 2010), this case illustrates the need for a closer analysis of the way in which scientific advice is transformed into actions by politicians and members of the public. Decision theorists may be able to help avoid catastrophes like the L'Aquila miscommunication in the future.

\section{Climategate closed}

\section{Climate science at the University of East Anglia is sound but lacking in transparency, according to the three official reports. But making data accessible will not be sufficient to guard against future attacks.}

The case of the alleged misbehaviour of climate researchers at the University of East Anglia is now closed. The last of the three reports on the science and conduct of the researchers was published on 7 July. Taken together, the independent investigations come to the conclusion that the scientific results produced at the University of East Anglia are sound, but that there are deficiencies in the transparency of climate research, at this university and elsewhere. In response to the reports, the data used in climate change studies should be made publicly available (Nature Geosci. 3, 218; 2010). But the critics are already crying "whitewash". More openness alone is unlikely to resolve tensions between scientists, the media and politicians, or between sceptics and alarmists.

Two Commentaries in this issue of Nature Geoscience, one by a climate scientist (page 511) and one by a social anthropologist (page 513) focus on the lessons learnt from last winter's media frenzy. They argue that climate scientists must engage in and inform discussions with the people who will feel the impact of climate change, to root their efforts in the global (and not just the scientific) community. Yet, at the same time, scientists need to be humble. Climate change projections are just one factor in any policy decision on adaptation or mitigation - and indeed, the only factor that climate researchers can expertly comment on.

The hacked e-mails reveal that such modesty seems to have been lacking at times (http://go.nature.com/k6Guis). For example, in an exchange in late July 1999, climate scientists discussed how to present projected climate change scenarios to best serve the purposes of the WWF (who had apparently expressed concern that the initial presentations were more conservative than those from other sources and asked for one section to be 'beefed up' if possible). Such considerations should not enter into scientific debate.

Furthermore, the e-mails are pervaded by a tendency to divide the world into friends and enemies. A curious contribution to the 'Letters' column in Science (Science doi:10.1126/science.280.5372.2027e; 1998) — stating that "the reader might see more disagreement than actually exists" between the hockey-stick paper (Nature 392, 779-787; 1998) and its early criticism (Science 280, 544-545; 1998) - suggests that initial differences between scientists were quickly ironed out to present a united front. Yet a polarized view of an issue as complex as climate change can only be an oversimplification.

Difficult as this may be, scientists have to maintain a disinterested perspective on the available information, be prepared to change their assessment when new facts come to light, and accept differences in opinion while taking counter-arguments seriously. Along with greater openness, a much more nuanced and multifaceted discussion of the physical aspects of climate change needs to be presented to the public to avoid future accusations of cliquiness and gatekeeping. 